\title{
A Note on Anaesthesia in Leprosy
}

B. Moiser.

Changes in tactile sensation in leprosy (heat and cold are not here considered), are often so slight that they escape detection altogether, and since the diagnosisin many cases depends upon them, it is important that tests be carried out in a most careful manner.

African natives vary much in their general sensibility to touch, so that this general sensibility must be gauged in each patient. Most normal people can feel a fly walking on the skin, especially on those parts which are clothed with short hairs, but there are others who do not respond to quite a heavy touch.

The general mental condition must also be gauged, and it is often necessary to spend considerable time in teaching the patient to respond to the least touch that he feels.

Having first set an estimate on these two conditions. tests for anaesthesia ca be commenced.

A piece of cotton wool appears to be the best means, rolled into a pencil, with one or two single fibres pulled out at the end. In many cases it is necessary to touch the skin 
with these single filsres alone, in order to detect the very minute changes in sensation which occur in leprosy.

A feather, light as it is, is much too heavy an object to use. A piece of pajer is useless, for it creates a sound besides being too stiff. With cotton wool the slightest changes become apparent. The amount of pressure employed can be varied within wide limits, and can be used to determine the depth of anaesthesia. Tapping the skin with the firmer portion of the wool is often of value.

Thumbs. For some reason or other, the thumbs of natives are curiously insensitive, and the cletermination of anaesthesia in these parts presents the greatest difficulty, and since the radial nerve is almost as frequently affected as the ulnar, the thumb is a matter of importance.

Dorsum of Foot. This area is very similar to the thumb in this respect, but the thin skin at the base of the toes is generally extremely sensitive, and is much more useful in the determination of anaesthesia than the dorsum.

Changes in sensation often precede changes in pigmentation, and can be readily as certained by the cotton wool method, but they require a great deal of time and patience.

At this hospital it is not possible to get ice-cold water, so that changes to heat and cold cannot be ascertained. 